\title{
Diversifiable and Non-diversifiable Risk and the Advanced Choice under Ambiguous or Uncertain Conditions
}

\author{
M.J. Alhabeeb ${ }^{1}$ \\ ${ }^{1}$ Professor, Department of Resource Economics, University of Massachusetts Amherst, United States \\ Correspondence: Prof. M.J. Alhabeeb, 44 Lyn Dr. Granby, MA 01033, United States.
}

Received: October 11, 2021

Accepted: November 7, 2021

Online Published: November 17, 2021

doi:10.5539/ibr.v14n12p96

URL: https://doi.org/10.5539/ibr.v14n12p96

\begin{abstract}
The objective of this paper is to revisit the concepts of diversifiable and non-diversifiable risk, expound the portfolio risk in two ways: mathematically first, and with practical examples, second It also explains lending and borrowing at the risk-free rate of return, in addition to juxtaposing the diversification method to measure the unsystematic risk against utilizing Beta to measure the systematic risk. Furthermore, it briefly examines the mathematical simulation and sensitivity analysis, and mathematically delineates the technique for choices under risk, ambiguity, and uncertainty. The practical implication of this conceptual paper is to offer a further clarification of theoretical terms, especially those which might be interchangeable in financial and economic literature, and further show, by examples, the terms' applicability.
\end{abstract}

Keywords: systematic risk, non-systematic risk, diversifiable risk, non-diversifiable risk, choice under ambiguity, choice under uncertainty

\section{Introduction}

Research on risk, its measurement and tolerance in the context of market and business investment has been around and been advancing for the last hundred years or so. Probably the economic approach goes back to the pioneering studies by Frank Knight at the start of the 1920's, and more specifically, the modern portfolio analysis goes back to the studies of Markowitz (1952), Modigliani and Miller (1958), and Sharpe (1964). With that relatively long history of literature, there has been a diversity of perceptions and a variety of applications, whose approaches depended on who was adopting them! whether they were academics and theorists, empirical researchers, or corporate practitioners. Theorists, for example, have realized the prevalent mix-ups in major concepts such as the typical confusion between the natures of uncertainty and ambiguity. On the other hand, the empirical researchers have discovered that some constructs such as the major statistical measures necessary for diversification like variance and covariance of security returns fluctuate over time, and they vary between short and long run. Realizing and being able to measure risk are essential inputs for the decision-making process, and both depend on context, which vary according to many factors such as the organizational structure and social and cultural effects, and for all this complexity, it is plausible to say that the nature, measurement, and tolerance of risk and uncertainty remain murky. The objective of this paper is to revisit the concepts of diversifiable and non-diversifiable risk, expound the portfolio risk in two ways: mathematically first, and with practical examples, second. It also explains lending and borrowing at the risk-free rate of return, in addition to juxtaposing the diversification method to measure the unsystematic risk against utilizing Beta to measure the systematic risk. Furthermore, it briefly examines the mathematical simulation and sensitivity analysis, and mathematically delineates the technique for choices under risk, ambiguity, and uncertainty. The practical implication of this conceptual paper is to offer a further clarification of theoretical terms, especially those which might be interchangeable in financial and economic literature, and further show, by examples, the terms' applicability.

\section{Diversifiable and Non-diversifiable Risk}

Diversifiable or unsystematic risk is the risk specific to an individual firm, as it is related to its internal conditions and circumstances such as lawsuits against the firm, marketing or accounting problems, product defect, workers' strike, problematic contracts, and so on. It is, therefore, the risk associated with a particular asset or project or the risk of an entire financial portfolio in an organizational level. This type of risk can be reduced or even eliminated by the classical remedy of the diversification of assets within the portfolios so that the no risky or less risky assets mitigate the risky ones. (Alhabeeb, 2013; Bay, 2003; Ben-Horim \& Levy, 1980; Gitman 2008). 
The non-diversifiable or systematic risk is the general and market-related risk that would affect all firms and all projects and assets, simultaneously and with no discrimination. It is associated with the state of the economy and structure of markets as well as with national and regional big events such as wars, political unrest, natural disasters, and severe weather. But the most striking impact of such external factors is the impact of those economic conditions such as recession, inflation, unemployment, and unusual interest rate fluctuations.

(Brigham and Houston, 1999; Fama and French, 1992; Fama, et al. 2004; Perold, 2004).

Unlike the unsystematic risk, systematic risk cannot be reduced or eliminated by diversification of assets. In fact, there is no other way to minimize it or remove its impact. However, it can be assessed by monitoring how a particular asset tends to respond to the market state and its changes. This is usually addressed by the Capital Asset Pricing Model CAPM where the systematic risk is measured by beta ( $\beta$ ). CAPM analysis is not included in this paper, but the following shall address in detail the unsystematic risk at the portfolio level and how it can be reduced by diversification of assets within a specific portfolio. (Acharya, 2017; Alhabeeb, 2010; Blokdyk, 2020; Hirshey, 2006; Kasser, 2020; Keat, 2006; Salvatore, 2012).

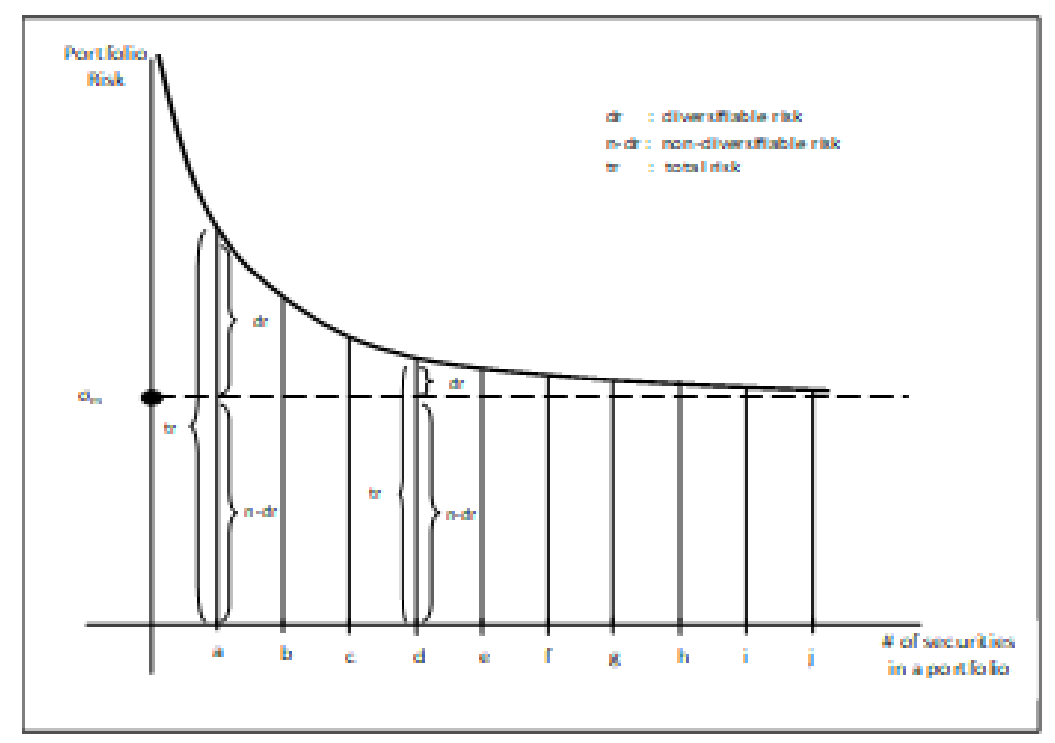

Figure 1. shows how portfolio risk tends to decline, as the financial portfolio includes more and more individual assets and securities

\section{Portfolio Risk}

There are two factors that would determine the risk level in a financial portfolio containing many individual assets and securities: 1) How diversified are the assets, since risk has a negative relationship with diversification. 2) How correlated are the asset since risk has a positive relationship with correlation of assets.

But more crucial is the degree and direction of correlation. Diversification of assets cannot reduce the risk level unless the assets are either negatively correlated or at least positively correlated but to a much lower degree. If they are strongly positively correlated, risk cannot be eliminated or reduced by merely diversifying the portfolio. The following Table 1 and Table 2 show two pairs of assets, X \& Y and Z \& W. Variance of the two sets of return were individually calculated at the $7^{\text {th }}$ and $12^{\text {th }}$ columns as:

$$
\sigma_{\mathrm{x}}^{2}=\sum_{\mathrm{i}=1}^{5}\left(\mathrm{k}_{\mathrm{i}}^{\mathrm{x}}-\mathrm{k}_{\mathrm{e}}^{\mathrm{x}}\right)^{2} \operatorname{Pr}_{\mathrm{i}}=.046 \quad \sigma_{\mathrm{y}}^{2}=\sum_{\mathrm{i}=1}^{5}\left(\mathrm{k}_{\mathrm{i}}^{\mathrm{y}}-\mathrm{k}_{\mathrm{e}}^{\mathrm{y}}\right)^{2} \operatorname{Pr}_{\mathrm{i}}=.067
$$

The standard deviations of the two sets of return were calculated as:

$$
\sigma_{\mathrm{x}}=\sqrt{\sum_{\mathrm{i}=1}^{5}\left(\mathrm{k}_{\mathrm{i}}^{\mathrm{x}}-\mathrm{k}_{\mathrm{e}}^{\mathrm{x}}\right)^{2} \operatorname{Pr}_{\mathrm{i}}}, \quad \sigma_{\mathrm{x}}=\sqrt{.046}=.214, \quad \sigma_{\mathrm{y}}=\sqrt{\sum_{\mathrm{i}=1}^{5}\left(\mathrm{k}_{\mathrm{i}}^{\mathrm{y}}-\mathrm{k}_{\mathrm{e}}^{\mathrm{y}}\right)^{2} \operatorname{Pr}_{\mathrm{i}}}, \quad \sigma_{\mathrm{y}}=\sqrt{.067}=.259
$$

The covariance between the two sets of return $\operatorname{cov}(\mathrm{x}, \mathrm{y})$ is also calculated at the $13^{\text {th }}$ column as: 


$$
\operatorname{cov}(\mathrm{x}, \mathrm{y})=\sum_{\mathrm{i}=1}^{5}\left(\mathrm{k}_{\mathrm{i}}^{\mathrm{x}}-\mathrm{k}_{\mathrm{e}}^{\mathrm{x}}\right)\left(\mathrm{k}_{\mathrm{i}}^{\mathrm{y}}-\mathrm{k}_{\mathrm{e}}^{\mathrm{y}}\right) \operatorname{Pr}_{\mathrm{i}}, \quad \operatorname{cov}(\mathrm{x}, \mathrm{y})=.0554
$$

and finally the correlation coefficient (COR) between the two sets of return is calculated as:

$$
\operatorname{COR}_{x, y}=\frac{\operatorname{cov}(x, y)}{\sigma_{x} \sigma_{y}}, \quad \operatorname{COR}_{x, y}=\frac{.0554}{(.214)(.259)}, \quad \operatorname{COR}_{x, y}=99.9 \%
$$

A correlation coefficient, which is large enough to be close to a $(+100)$ would be considered a solid indication of a perfectly positively correlated assets. It means that they exhibit a similar dynamic that makes them move together, up and down, in tandem. This kind of matching pattern would not benefit from diversification in risk reduction at all. The left panel of Figure2 shows such a synchronized movement of the returns of those assets.
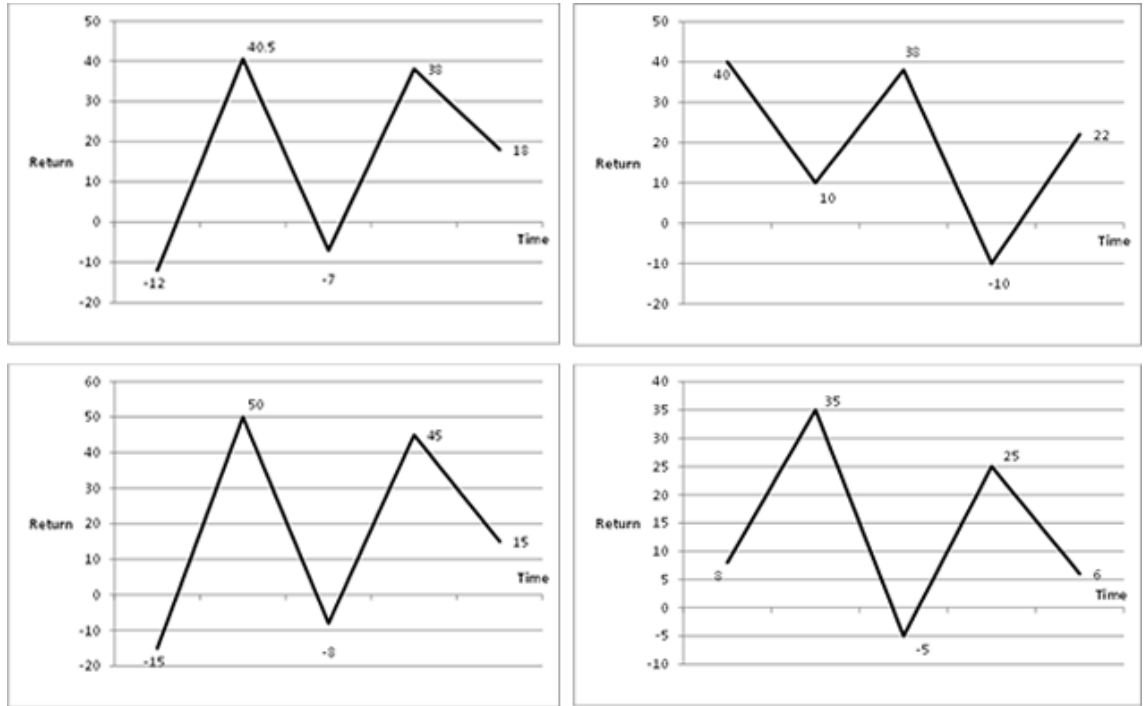

Figure 2. The synchronized movement of the returns of assets

The second set of assets, $\mathrm{Z}$ and $\mathrm{W}$, is presented in Table $\mathrm{ZW}$ and the same parameters are calculated in the same manner they were calculated in table XY.

The variances of the assets are at columns 7 and 12:

$$
\sigma_{\mathrm{Z}}^{2}=\sum_{\mathrm{i}=1}^{5}\left(\mathrm{k}_{\mathrm{i}}^{\mathrm{Z}}-\mathrm{k}_{\mathrm{e}}^{\mathrm{Z}}\right)^{2} \operatorname{Pr}_{\mathrm{i}}, \quad \sigma_{\mathrm{Z}}^{2}=.0339, \quad \sigma_{\mathrm{W}}^{2}=\sum_{\mathrm{i}=1}^{5}\left(\mathrm{k}_{\mathrm{i}}^{\mathrm{W}}-\mathrm{k}_{\mathrm{e}}^{\mathrm{W}}\right)^{2} \operatorname{Pr}_{\mathrm{i}}, \quad \sigma_{\mathrm{W}}^{2}=.0129
$$

and the standard deviations are:

$$
\sigma_{\mathrm{Z}}=\sqrt{.0339}=.1841, \quad \sigma_{\mathrm{W}}=\sqrt{.0129}=.1136
$$

The covariance is: $\operatorname{cov}(\mathrm{z}, \mathrm{w})=\sum_{\mathrm{i}=1}^{5}\left(\mathrm{k}_{\mathrm{i}}^{\mathrm{Z}}-\mathrm{k}_{\mathrm{e}}^{\mathrm{Z}}\right)\left(\mathrm{k}_{\mathrm{i}}^{\mathrm{W}}-\mathrm{k}_{\mathrm{e}}^{\mathrm{W}}\right)^{2} \operatorname{Pr}_{\mathrm{i}}, \quad \operatorname{cov}(\mathrm{z}, \mathrm{w})=-.020353$

The correlation coefficient is: $\operatorname{COR}_{\mathrm{z}, \mathrm{w}}=\frac{\operatorname{cov}(\mathrm{z}, \mathrm{w})}{\sigma_{\mathrm{x}} \sigma_{\mathrm{w}}}, \mathrm{COR}_{\mathrm{z}, \mathrm{w}}=\frac{-.020353}{(.1841)(.1136)}=-97.3 \%$ 
Table 1. $\mathrm{X}$ and $\mathrm{Y}$ assets and their variance inputs

\begin{tabular}{|c|c|c|c|c|c|c|c|c|c|c|c|c|}
\hline \multirow[b]{2}{*}{1} & \multirow[b]{2}{*}{2} & \multicolumn{5}{|c|}{ Asset X } & \multicolumn{4}{|c|}{ Asset $Y$} & \multirow[b]{2}{*}{12} & \multirow[b]{2}{*}{13} \\
\hline & & 3 & 4 & 5 & 6 & 7 & 8 & 9 & 10 & 11 & & \\
\hline & $\operatorname{Pr}_{i}$ & $\mathrm{k}_{\mathrm{i}}^{\mathrm{x}}$ & $\mathrm{k}_{\mathrm{e}}^{\mathrm{x}}$ & $\begin{array}{l}\mathrm{k}_{\mathrm{i}}^{\mathrm{x}}- \\
\mathrm{k}_{\mathrm{e}}^{\mathrm{x}}\end{array}$ & $\begin{array}{l}\left(\mathrm{k}_{\mathrm{i}}^{\mathrm{x}}-\right. \\
\left.\mathrm{k}_{\mathrm{e}}^{\mathrm{x}}\right)^{2}\end{array}$ & $\begin{array}{l}\left(\mathrm{k}_{\mathrm{i}}^{\mathrm{x}}-\right. \\
\left.\mathrm{k}_{\mathrm{e}}^{\mathrm{x}}\right)^{2}\end{array}$ & $\mathrm{k}_{\mathrm{i}}^{\mathrm{y}}$ & $\mathrm{k}_{\mathrm{e}}^{\mathrm{y}}$ & $\begin{array}{l}\left(\mathrm{k}_{\mathrm{i}}^{\mathrm{y}}-\right. \\
\left.\mathrm{k}_{\mathrm{e}}^{\mathrm{y}}\right)\end{array}$ & $\begin{array}{l}\left(\mathrm{k}_{\mathrm{i}}^{\mathrm{y}}-\right. \\
\left.\mathrm{k}_{\mathrm{e}}^{\mathrm{y}}\right)^{2}\end{array}$ & $\begin{array}{c}\left(\mathrm{k}_{\mathrm{i}}^{\mathrm{y}}-\right. \\
\left.\mathrm{k}_{\mathrm{e}}^{\mathrm{y}}\right)^{2} \operatorname{Pr}_{\mathrm{i}}\end{array}$ & $\begin{array}{c}\left(\mathrm{k}_{\mathrm{i}}^{\mathrm{x}}-\mathrm{k}_{\mathrm{e}}^{\mathrm{x}}\right)\left(\mathrm{k}_{\mathrm{i}}^{\mathrm{y}}-\right. \\
\left.\mathrm{k}_{\mathrm{e}}^{\mathrm{y}}\right) \operatorname{Pr}_{\mathrm{i}}\end{array}$ \\
\hline $\mathrm{k}_{1}$ & .20 & -.12 & .155 & -.275 & .0756 & .015 & -.15 & .174 & -.324 & .105 & .021 & .0178 \\
\hline $\mathrm{k}_{2}$ & .15 & .405 & .155 & .25 & .0625 & .0094 & .50 & .174 & .326 & .1063 & .016 & .0122 \\
\hline $\mathrm{k}_{3}$ & .25 & -.07 & .155 & -.225 & .0506 & .0126 & -.08 & .174 & -.254 & .0645 & .016 & .0143 \\
\hline $\mathrm{k}_{4}$ & .18 & .38 & .155 & .225 & .0506 & .0091 & .45 & .174 & .276 & .0762 & .014 & .0112 \\
\hline $\mathrm{k}_{5}$ & .22 & .18 & .155 & .025 & .000625 & .00014 & .15 & .174 & -.024 & .00058 & .00013 & -.00013 \\
\hline & & & & & & .046 & & & & & .067 & .0554 \\
\hline
\end{tabular}

Table 2. $\mathrm{Z}$ and $\mathrm{W}$ assets and their variance inputs

\begin{tabular}{|c|c|c|c|c|c|c|c|c|c|c|c|c|}
\hline & & \multicolumn{5}{|c|}{ Asset Z } & \multicolumn{4}{|c|}{ Asset W } & \multirow[b]{2}{*}{12} & \multirow[b]{2}{*}{13} \\
\hline 1 & 2 & 3 & 4 & 5 & 6 & 7 & 8 & 9 & 10 & 11 & & \\
\hline & $\mathrm{Pr}_{\mathrm{i}}$ & $\mathrm{k}_{\mathrm{i}}^{\mathrm{z}}$ & $\mathrm{k}_{\mathrm{e}}^{\mathrm{z}}$ & $\begin{array}{l}\mathrm{k}_{\mathrm{i}}^{\mathrm{z}}- \\
\mathrm{k}_{\mathrm{e}}^{\mathrm{z}}\end{array}$ & $\begin{array}{l}\left(\mathrm{k}_{\mathrm{i}}^{\mathrm{z}}-\right. \\
\left.\mathrm{k}_{\mathrm{e}}^{\mathrm{z}}\right)^{2}\end{array}$ & $\begin{array}{c}\left(\mathrm{k}_{\mathrm{i}}^{\mathrm{z}}-\right. \\
\left.\mathrm{k}_{\mathrm{e}}^{\mathrm{z}}\right)^{2} \operatorname{Pr}_{\mathrm{i}}\end{array}$ & $\mathrm{k}_{\mathrm{i}}^{\mathrm{w}}$ & $\mathrm{k}_{\mathrm{e}}^{\mathrm{w}}$ & $\begin{array}{l}\left(\mathrm{k}_{\mathrm{i}}^{\mathrm{w}}-\right. \\
\left.\mathrm{k}_{\mathrm{e}}^{\mathrm{w}}\right)\end{array}$ & $\begin{array}{l}\left(\mathrm{k}_{\mathrm{i}}^{\mathrm{w}}-\right. \\
\left.\mathrm{k}_{\mathrm{e}}^{\mathrm{w}}\right)^{2}\end{array}$ & $\begin{array}{l}\left(\mathrm{k}_{\mathrm{i}}^{\mathrm{w}}-\right. \\
\left.\mathrm{k}_{\mathrm{e}}^{\mathrm{w}}\right)^{2} \operatorname{Pr}_{\mathrm{i}}\end{array}$ & $\begin{array}{c}\left(\mathrm{k}_{\mathrm{i}}^{\mathrm{z}}-\mathrm{k}_{\mathrm{e}}^{\mathrm{z}}\right)\left(\mathrm{k}_{\mathrm{i}}^{\mathrm{w}}-\right. \\
\left.\mathrm{k}_{\mathrm{e}}^{\mathrm{w}}\right) \operatorname{Pr}_{\mathrm{i}}\end{array}$ \\
\hline $\mathrm{k}_{1}$ & .20 & .40 & .20 & .20 & .04 & .008 & .08 & .138 & -.058 & .0034 & .00068 & -.00232 \\
\hline $\mathrm{k}_{2}$ & .15 & .10 & .20 & -.10 & .01 & .0015 & .35 & .138 & .212 & .045 & .00675 & -.00318 \\
\hline $\mathrm{k}_{3}$ & .25 & .38 & .20 & .18 & .0324 & .0081 & -.05 & .138 & -.188 & .0077 & .001925 & -.00846 \\
\hline $\mathrm{k}_{4}$ & .18 & -.10 & .20 & .30 & .09 & .0162 & .25 & .138 & .112 & .0125 & .00225 & -.00605 \\
\hline $\mathrm{k}_{5}$ & .22 & .22 & .20 & .02 & .0004 & .000088 & .06 & .138 & -.078 & .0061 & .001342 & -.000343 \\
\hline & & & & & & .0339 & & & & & .0129 & -.020353 \\
\hline
\end{tabular}

A correlation coefficient of $-97.3 \%$ shows the opposite case of X \& Y combination. It indicates that assets $\mathrm{Z}$ and $\mathrm{W}$ are almost perfectly negatively correlated, which means that the return changes of these assets go up and down, opposite to each other.

This is the ideal case to offer the opportunity for these assets to cancel each other out. If one is down, the other is up to compensate. That is the beauty of diversification. The combination of such assets in a portfolio gives the opportunity to have an optimal impact of diversifying the risk away. The right panel of Figure 2 shows how the return patterns act opposite each other in a consistently contrasting manner.

Combining assets into portfolios would most likely reduce the risk even for those assets that are positively correlated. In the two tables, $1 \& 2$, we combined asset $\mathrm{X}$ and asset $\mathrm{Y}$ and obtained an average vector of returns for the combination xy. Also, we combined asset $\mathrm{Z}$ and $\mathrm{W}$ and obtained an average vector of returns for the combination ZW. The standard deviation test showed that the combination helps reduce risk even for combining 
$\mathrm{x}$ and $\mathrm{y}$ which are perfectly positively correlated as we have seen. The standard deviation of the combined set $\mathrm{XY}\left(\sigma_{\mathrm{xy}}=-195\right)$ is still less than either of the asset taken individually where $\sigma_{\mathrm{x}}=.214$, and $\sigma_{\mathrm{y}}=.259$. This means that the combined assets showed that it is not as risky as either of the individual assets standing alone. This standard deviation test shows much better results when we combined the negatively correlated assets $\mathrm{Z}$ and $\mathrm{W}$. The standard deviation of the combined set $\mathrm{ZW}$ is

$\left(\sigma_{\mathrm{zW}}=.056\right)$ which is much less than either of the assets' standard deviation where $\sigma_{\mathrm{z}}=.1841$ and

$\sigma_{\mathrm{w}}=.1136$. It is a further proof that combining assets into portfolios would increase diversification and reduce risk. However, the extent of risk reduction depends primarily on the degree and sign of the correlation between the assets.

\section{Combined Assets xy With Average Returns}

Table 3. Combined assets, $\mathrm{X}$ and $\mathrm{Y}$

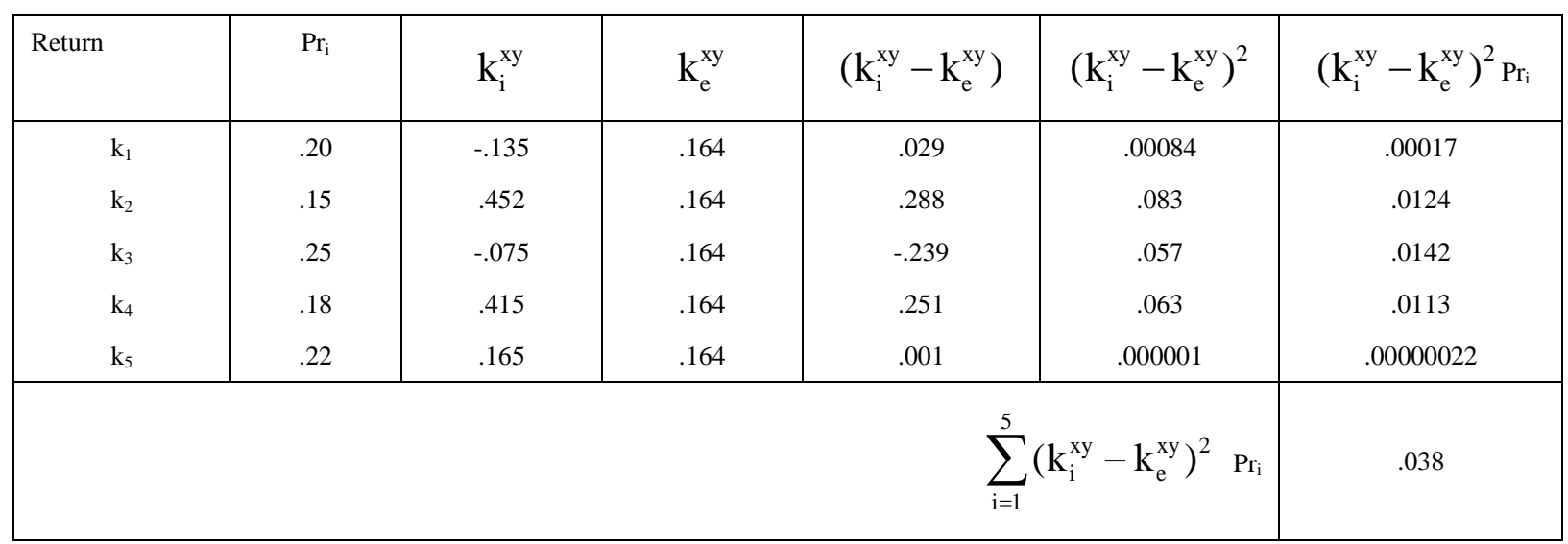

Combined Assets zw with Average Returns

Table 4. Combined assets, $\mathrm{Z}$ and $\mathrm{W}$

\begin{tabular}{|c|c|c|c|c|c|c|}
\hline Return & $\operatorname{Pr}_{\mathrm{i}}$ & $\mathrm{k}_{\mathrm{i}}^{\mathrm{zw}}$ & $\mathrm{k}_{\mathrm{e}}^{\mathrm{zW}}$ & $\left(\mathrm{k}_{\mathrm{i}}^{\mathrm{ZW}}-\mathrm{k}_{\mathrm{e}}^{\mathrm{ZW}}\right)$ & $\left(\mathrm{k}_{\mathrm{i}}^{\mathrm{zw}}-\mathrm{k}_{\mathrm{e}}^{\mathrm{zw}}\right)^{2}$ & $\left(\mathrm{k}_{\mathrm{i}}^{\mathrm{zw}}-\mathrm{k}_{\mathrm{e}}^{\mathrm{zw}}\right)^{2} \operatorname{Pr}_{\mathrm{i}}$ \\
\hline $\mathrm{k}_{1}$ & .20 & .24 & .169 & .071 & .00504 & .001 \\
\hline $\mathrm{k}_{2}$ & .15 & .225 & .169 & .056 & .00314 & .00047 \\
\hline $\mathrm{k}_{3}$ & .25 & .165 & .169 & -.004 & .000016 & .000004 \\
\hline $\mathrm{k}_{4}$ & .18 & .075 & .169 & -.094 & .00884 & .00159 \\
\hline $\mathrm{k}_{5}$ & .22 & .14 & .169 & -.029 & .00084 & .00018 \\
\hline \multicolumn{6}{|c|}{$\sum_{\mathrm{i}=1}^{5}\left(\mathrm{k}_{\mathrm{i}}^{\mathrm{zw}}-\mathrm{k}_{\mathrm{e}}^{\mathrm{zW}}\right)^{2} \operatorname{Pr}_{\mathrm{i}}$} & .0032 \\
\hline
\end{tabular}

Most of the assets are positively correlated. Studies show that on average, randomly selected assets show a correlation coefficient around .60. The lower the positive correlation, the better results of the combination.

In an abstract presentation, Figure3 shows three possible ways to combine two assets in a portfolio, two extreme combinations and one common combination. The assets are: $\mathrm{A}$ with an expected return of $\mathrm{k}_{\mathrm{A}}$ and $\mathrm{k}_{\mathrm{B}}$ and risk level of $\sigma_{A}$, and $B$ with an expected higher return of $k_{B}$ and higher risk level $\sigma_{B}$. The first extreme case of combination occurs at any point along the straight-line $\mathrm{AB}$ if assets $\mathrm{A}$ and $\mathrm{B}$ are perfectly positively correlated. This combination cannot benefit much from diversification. The second extreme case of combination occurs at any point along BCA where a zero risk can be achieved with a rate of return equal to $\mathrm{k}_{\mathrm{c}}$ when the allocation of 
the two assets can be achieved in reverse proportion to their risk levels. This combination is the show case for the benefit of diversification. The third case of combination occurs at any point along the curve BA. It is the most likely case to occur because assets are often neither negatively nor positively perfectly correlated. The correlation would often be in a moderate level and the combination of assets can enjoy a wide range of returns from $\mathrm{k}_{\mathrm{A}}$ to $\mathrm{k}_{\mathrm{B}}$ for a wide range of risk level from $\sigma_{\mathrm{A}}$ to $\sigma_{\mathrm{B}}$. The curve would include all the possible combinations that are better alternatives to any point along the straight line $\mathrm{AB}$ but lower alternatives to most of the points along BCA which would offer higher rates of return for the same level of risk, especially along the segment BD.

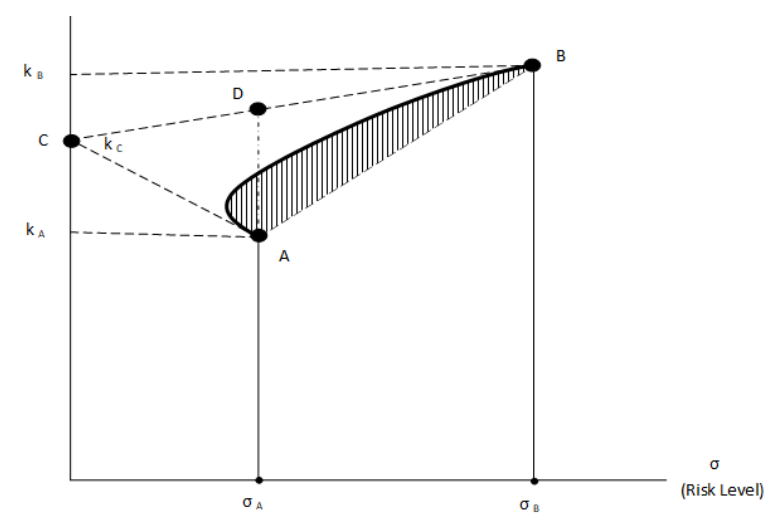

Figure 3. Three ways to combine two assets in a portfolio

\section{Risk of Two-Asset Portfolio}

Among the major issues addressed by Markowitz in his pioneering study of 1952 is portfolio diversification of assets, and the positive outcome on portfolio's return and risk through the compensatory effect of the assets that move in different directions. (Markowitz, 1952; Markowitz 1959, Tobin, 1958).

The left side of Figure 4 shows what happens if an investor decides to invest in two different choices of stocks, Stock I with an expected return of $8 \%$ and a low risk (represented by the standard deviation of return) of 15\%, Stock II which offers a higher return of $12 \%$ but at a higher risk of $22 \%$. The logical expectation is to calculate the combined return and risk for the mix if we know how much investment the investor is willing to dedicate to each of the stocks. Let's assume that this portfolio manager is willing to dedicate $55 \%$ of investment to Stock I and $45 \%$ to Stock II. The portfolio rate of return would be calculated as the weighted average of two returns: $\mathrm{k}_{\mathrm{p}}$ $=\mathrm{w}_{1} \mathrm{k}_{1}+\mathrm{w}_{2} \mathrm{k}_{2}, \mathrm{k}_{\mathrm{p}}=(.55)(.08)+(.45)(.12), \mathrm{k}_{\mathrm{p}}=9.8 \%$

As for the portfolio risk, it would be determined by the standard deviation of the combined assets given a correlation between the two assets of 38 .

$$
\begin{gathered}
\sigma_{\mathrm{I}, \mathrm{II}}=\sqrt{\sigma_{\mathrm{I}}^{2} \mathrm{w}_{\mathrm{I}}^{2}+\sigma_{\mathrm{II}}^{2} \mathrm{w}_{\mathrm{II}}^{2}+2 \mathrm{COR}_{\mathrm{I}, \mathrm{II}}\left(\mathrm{w}_{\mathrm{I}} \sigma_{\mathrm{I}}\right)\left(\mathrm{w}_{\mathrm{II}} \sigma_{\mathrm{II}}\right)} \\
\sigma_{\mathrm{I}, \mathrm{II}}=\sqrt{(.15)^{2}(.55)^{2}+(.22)^{2}(.45)^{2}+2(.38)(.55)(.15)(.45)(.22)}, \sigma_{\mathrm{I}, \mathrm{II}}=\sqrt{.0228}=15.1 \%
\end{gathered}
$$

So the risk level of the combined stocks in an asset is less than the weighted average risk of the two individual assets which would have been: $(.55)(.15)+(.45)(.22)=18.2 \%$ 

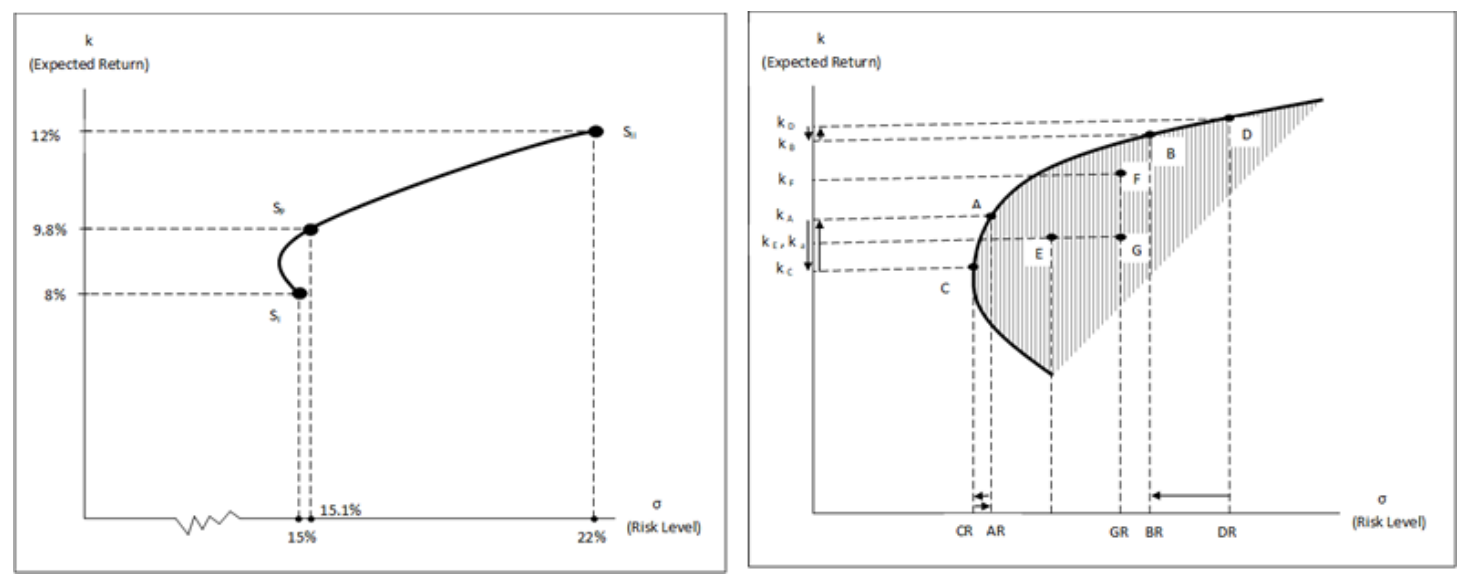

Figure 4 (left). Investing in two different choices of stocks

Figure 4 (right). Many assets in a larger number of combinations

Therefore, a combination of assets at $\mathrm{S}_{\mathrm{p}}$ would yield a 9.8\% rate of return at a reasonable level of risk of $15.1 \%$. If we generalize this hypothetical example to the real market with many assets in a larger number of combinations and producing a larger number of portfolios, we will get the broken-egg shaped area as it is shown on the right side of Figure 4. It shows all the combinations of assets that are attainable to all investors with their different objectives and different risk and return preferences. The following are some major observations on this graph: 1) The solid line curve represents the diversified portfolios with the highest returns for any given risk level between CR and DR. Markowitz called this curve the "efficient portfolio curve". It is also called the "frontier of risky portfolios". 2) Point $\mathrm{D}$ is the portfolio that yields the highest return $\left(\mathrm{k}_{\mathrm{D}}\right)$ but bears the highest level of risk (DR). 3) Point $\mathrm{C}$ is the portfolio that yields the lowest return $\left(\mathrm{k}_{\mathrm{C}}\right)$ but enjoys the lowest level of risk (CR). 4) Segment DB contains a collection of portfolios that enjoy a tradeoff between risk and return in favor of the risk side. For example, moving from $\mathrm{D}$ to $\mathrm{B}$ means getting a slightly less return than $\mathrm{k}_{\mathrm{D}}$ but for more reduction in risk level, DR to BR. Similarly, moving from B to D means gaining a slightly more return than $\mathrm{k}_{\mathrm{B}}$ but carrying more risk BR to DR. 5) Segment AC contains a collection of portfolios that enjoy a tradeoff between risk and return in favor of the return. For example, moving from $\mathrm{A}$ to $\mathrm{C}$ means accepting more reduction in return, from $\mathrm{k}_{\mathrm{A}}$ to $\mathrm{k}_{\mathrm{C}}$ for less reduction in risk, from AR to CR. Similarly, moving from $\mathrm{C}$ to A means getting much higher return for accepting a little more risk, from CR to AR. 6) Segment AB contains all the portfolios that exhibit an almost equal tradeoff between risk and return. In other words, gaining or losing a certain amount of return comes with gaining or losing a compatible amount of risk. 7) Inside the shape, we can observe that moving towards the northeast means getting portfolios with higher return and higher risk. On the contrary, moving towards the southwest means getting portfolios with lower return and lower risk. 8) Portfolio F is preferred to portfolio $\mathrm{G}$ because it yields more return for the same amount of risk. 9) Portfolio E is preferred to portfolio $\mathrm{G}$ because it enjoys a much lower level of risk for the same rate of return.

\section{Lending and Borrowing at the Risk-Free Rate of Return}

Let's assume that an investor wants to split his initial investment between asset A on the efficient portfolio curve and the treasury bills which offers a risk-free rate of return equal to 5\%. Suppose that A yields $12 \%$ at a risk level of $15 \%$. The investor would like to have $60 \%$ of his money invested in asset A and $40 \%$ invested in the treasury bills. 


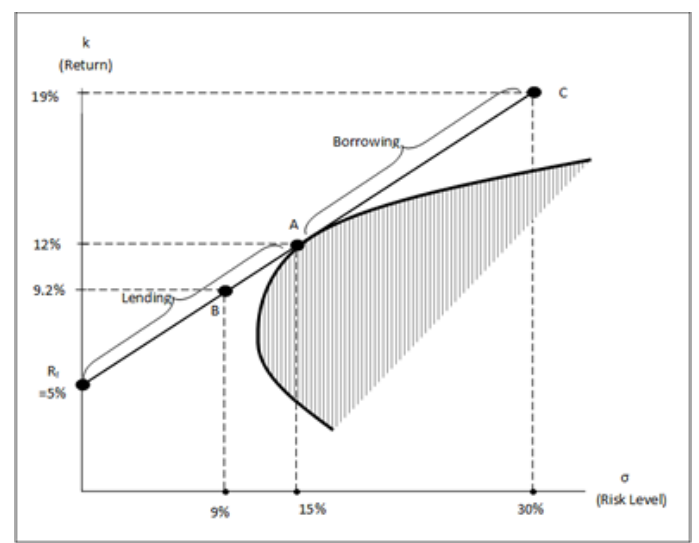

Figure 5. Splitting investment between a certain return and treasury bills

The investor in this case is lending $40 \%$ of his money to the treasury bills. His rate of return would be: $(.40)(.05)$ $+(.60)(.12)=9.2 \%$, and his level of risk: $(.40)(0)+(.60)(.15)=9 \%$

$\mathrm{He}$ would be at point $\mathrm{B}$ on Figure 5. This means that he could be at any point along the line $A \mathrm{R}_{\mathrm{f}}$ depending on the proportions of his investment between asset $\mathrm{A}$ and the treasury bills.

Now, let's assume that he borrows at the risk-free rate of $5 \%$ an amount of money equal to his own money and invest the total of his own and the borrowed money in asset A alone. His return would be: (2)(.12) - (.05) =19\%, and his risk would be: $(2)(.15)+(.05)(0)=30 \%$

$\mathrm{He}$ would be at point $\mathrm{C}$ which means that he could be at any point along $\mathrm{CA}$ depending on how much he borrows and how much risk he tolerates.

\section{Measuring the Systematic Risk by Beta $(\beta)$}

Beta $(\boldsymbol{\beta})$ is a mathematical tool to measure the systematic undiversifiable market risk. It is, in this sense, an index of the extent to which a security return moves in response to the changes in the overall market. This would make it as a measure of the securities volatility in relation to an average security represented by the state of the market. Market return is an aggregate measure of the return of all traded securities in the market at a specific time. Beta value can be positive or negative. Generally, it ranges between -2.5 to 2.5. The value of 1.00 denotes the full impact of market risk. Any individual security with a beta of 1.00 indicates that the return pattern of that security moves up and down perfectly with the market return. The value of zero refers to a total independence from the market impact. A value of more than 1.00 , such as 2.00 , reveals that the security is twice as volatile as the average security in the market. A negative value says that the asset return pattern moves in opposite direction to the market. Mathematically, Beta is obtained by dividing the covariance between the individual security return

$\left(\mathrm{k}_{\mathrm{i}}\right)$ and the market return $\left(\mathrm{k}_{\mathrm{m}}\right)$ by the variance of market return $(\mathrm{km}) . \quad \beta=\frac{\operatorname{COV}\left(\mathrm{k}_{\mathrm{i}}, \mathrm{k}_{\mathrm{m}}\right)}{\operatorname{Var}\left(\mathrm{k}_{\mathrm{m}}\right)}$

In this sense, Beta is a concept of correlation to assess how one security return is correlated with the rest in the market. From another perspective, Beta measures the percentage change in one security return as it responds to the changes in the external market return. It can be, therefore, interpreted as the financial elasticity of the change in a given asset relative to market change. Accordingly, Beta becomes the slope of the regression line between

the changes in market return and the corresponding response of the asset return. Beta $=\beta=\frac{\Delta Y}{\Delta X}$

If we track down the change in the market rate when it increases from 7.3 to 9.3 , the linear equation line of $y=$ 
$-8+1.5 \mathrm{x}$ would allow the return of the asset $\mathrm{k}_{\mathrm{i}}$ to increase from 3 to 6 . Therefore, we can obtain the slope of the line: Slope $=\frac{\Delta Y}{\Delta X}=\frac{6-3}{9.3-7.3}=\frac{3}{2}=1.5$

which is the value of $\beta$ in the equation of the line. This says that the asset rate of return follows the market return more with it but even more robustly. Its volatility as one and a half as the volatility of the market return. For example, if the market rate increases by $5 \%$, this asset's rate would increase by $7.5 \%$. We can also calculate Beta value by the formula method. For example, we can calculate Beta for x-corporation given 10 periodic rates of return $\left(\mathrm{k}_{\mathrm{i}}^{\mathrm{m}}\right)$ and market rates for the same period $\left(\mathrm{k}_{\mathrm{i}}^{\mathrm{m}}\right)$. In Table 5, we calculate the expected return of both as the averages $\left(\mathrm{k}_{\mathrm{e}}^{\mathrm{x}}\right)$ and $\left(\mathrm{k}_{\mathrm{e}}^{\mathrm{m}}\right)$, and we proceed to calculate the covariance between the two sets of rates and the variance of the market. Beta would be calculated by dividing the covariance by the market variance.

Table 5. Elements to calculate Beta

\begin{tabular}{|c|c|c|c|c|c|c|c|c|}
\hline \multicolumn{4}{|c|}{$\mathrm{x}$-corporation } & \multicolumn{5}{|c|}{ Market } \\
\hline Period & $\mathrm{k}_{\mathrm{i}}^{\mathrm{x}}$ & $\mathrm{k}_{\mathrm{e}}^{\mathrm{x}}$ & $\left(\mathrm{k}_{\mathrm{i}}^{\mathrm{x}} \mathrm{k}_{\mathrm{e}}^{\mathrm{x}}\right)$ & $\mathrm{k}_{\mathrm{i}}^{\mathrm{m}}$ & $\mathrm{k}_{\mathrm{e}}^{\mathrm{m}}$ & $\left(\mathrm{k}_{\mathrm{i}}^{\mathrm{m}} \mathrm{k}_{\mathrm{e}}^{\mathrm{m}}\right)$ & $\left(\mathrm{k}_{\mathrm{i}}^{\mathrm{m}} \mathrm{k}_{\mathrm{e}}^{\mathrm{m}}\right)^{2}$ & $\begin{array}{c}\left(\mathrm{k}_{\mathrm{i}}^{\mathrm{x}} \mathrm{k}_{\mathrm{e}}^{\mathrm{x}}\right)\left(\mathrm{k}_{\mathrm{i}}^{\mathrm{m}}\right. \\
\left.\mathrm{k}_{\mathrm{e}}^{\mathrm{m}}\right)\end{array}$ \\
\hline 1 & -.06 & .105 & -.165 & .027 & .082 & -.055 & .003 & .0091 \\
\hline 2 & .27 & .105 & .165 & .095 & .082 & .013 & .00017 & .0021 \\
\hline 3 & .065 & .105 & -.04 & .038 & .082 & -.044 & .0019 & .0018 \\
\hline 4 & .13 & .105 & .025 & .055 & .082 & -.027 & .00073 & -.00067 \\
\hline 5 & .055 & .105 & -.05 & -.017 & .082 & -.099 & .0098 & .0049 \\
\hline 6 & .28 & .105 & .175 & .176 & .082 & .094 & .0088 & .0164 \\
\hline 7 & -.045 & .105 & -.15 & .119 & .082 & .037 & .0014 & -.0055 \\
\hline 8 & .03 & .105 & -.075 & .128 & .082 & .046 & .0021 & -.0034 \\
\hline 9 & .35 & .105 & .245 & .156 & .082 & .074 & .0055 & .0181 \\
\hline 10 & -.025 & .105 & -.13 & .044 & .082 & -.038 & .0014 & .0049 \\
\hline & & & & & & & .0348 & .04773 \\
\hline
\end{tabular}

$\operatorname{cov}(\mathrm{x}, \mathrm{m})=\frac{\sum_{\mathrm{i}=1}^{10}\left(\mathrm{k}_{\mathrm{i}}^{\mathrm{x}}-\mathrm{k}_{\mathrm{e}}^{\mathrm{x}}\right)\left(\mathrm{k}_{\mathrm{i}}^{\mathrm{m}}-\mathrm{k}_{\mathrm{e}}^{\mathrm{m}}\right)}{\mathrm{N}}, \operatorname{cov}(\mathrm{x}, \mathrm{m})=\frac{.04773}{10}=.0048, \quad \operatorname{var}(\mathrm{m})=\frac{\sum_{\mathrm{i}=1}^{10}\left(\mathrm{k}_{\mathrm{i}}^{\mathrm{m}}-\mathrm{k}_{\mathrm{e}}^{\mathrm{m}}\right)^{2}}{\mathrm{~N}}$

$$
\operatorname{var}(\mathrm{m})=\frac{.0348}{10}=.0035, \beta_{\mathrm{x}}=\frac{\operatorname{cov}(\mathrm{x}, \mathrm{m})}{\operatorname{var}(\mathrm{m})}, \beta_{\mathrm{x}}=\frac{.0048}{.0035}=1.37, \beta_{\mathrm{p}}=\sum_{\mathrm{i}=1}^{\mathrm{n}} \beta_{\mathrm{i}} \mathrm{w}_{\mathrm{i}}
$$


Note that $\beta_{\mathrm{x}}$ is just the beta of Asset X. A portfolio beta would be weighted average of betas for all individual assets within the portfolio, where $\beta_{\mathrm{p}}$ is the portfolio beta, $\beta_{\mathrm{i}}$ is the beta for any individual asset within the portfolio, $w_{i}$ is the proportion of asset $i$ out of the entire portfolio that contains $n$-assets.

\section{Mathematical Simulation and Sensitivity Analysis}

We have seen some iconic models in the physical world of design and engineering, which are made to reduce the potential risks, explore flaws, and enhance positive features, as well as estimate costs. Mathematical simulation models are designed to mimic the realities of the business world and deal with their changes. They present yet, another technique that would assist the decision maker in exploring all the possibilities surrounding the problem at hand when it comes to dealing with risky and uncertain conditions. The essential features of the real world can be translated into a multivariable model, complete with estimations of the probability distributions of the key variables. The model can be tested repeatedly with random values which are given to the variables in each test until a probability distribution and risk for the general model is estimated so that it can be used to calculate the expected outcome for any given variables. Let's assume that we want to estimate the net present value of a project and explore the risk involved. We can simulate the profit model and randomize the values of its variables many times and calculate the probability distribution and the standard deviation so that they become the template for estimating the net present value at any risky circumstances. We can start with a mathematical formula to represent the profit as a net cash flow for the t-period $\left(\pi_{t}\right)$ :

$$
\pi_{t}=[R-C-D](1-x)+D
$$

$R$ is the total revenue, which is equal to the amount of product sold (s) times the product unit price (p). $R=s(p)$,

$\mathrm{C}$ is the total cost, which is equal to the amount of product sold (s) times the unit cost, including production $\operatorname{cost}\left(c_{1}\right)$ and selling cost $\left(c_{2}\right) . C=s\left(c_{1}+c_{2}\right)$, D is the annual depreciation, which is equal to the original

depreciable cost and initial capital outlay divided by the lifetime of the physical capital asset. $D=\frac{d}{L}, \quad x$ is the marginal tax rate, where the profit is adjusted accordingly by $(1-\mathrm{x})$.

$\pi_{\mathrm{t}}-\left[\mathrm{s}(\mathrm{p})-\mathrm{s}\left(\mathrm{c}_{1}+\mathrm{c}_{2}\right)-\frac{\mathrm{d}}{\mathrm{L}}\right](1-\mathrm{x})+\frac{\mathrm{d}}{\mathrm{L}}$. Now, let's give these variables their numerical values: product

sold $(\mathrm{s})=5,000$ unit, product unit price $(\mathrm{p})=\$ 15$, production cost per unit $\left(\mathrm{c}_{1}\right)=\$ 2.50$, selling cost per unit $\left(\mathrm{c}_{2}\right)$ $=\$ .50$, original equipment depreciation $(\mathrm{d})=\$ 18,000$, equipment lifetime $(\mathrm{L})=10$ years, marginal tax rate $(\mathrm{x})=$ $36 \%$

Profit $\pi_{\mathrm{t}}$ would be:

$$
\pi_{\mathrm{t}}=\left[5,000(15)-5,000(2.50+.50)-\frac{8,000}{10}\right](1-.36)+\frac{8,000}{10}, \quad \pi_{\mathrm{t}}=38,688
$$

The $\$ 38,688$ is the profit earned for the period t. If we assume that it will be earned in every year of the project life for the next 4 years $(n=4)$, then the net present value for the cash flow during the entire period of $n$ would be:

$$
\mathrm{NPV}_{\mathrm{n}}=\sum_{\mathrm{t}=1}^{\mathrm{n}} \frac{\pi_{\mathrm{t}}}{(1+\mathrm{k})^{\mathrm{t}}}-\mathrm{C}_{0}
$$

Given that the risk-free rate of interest ( $r)$ is $5 \%$ and the firm's risk premium $\left(R_{p}\right)$ is $7 \%$, then $k$ would be: $k=r+$ $\mathrm{R}_{\mathrm{p},}=.05+.07=.12$. If the initial cost of the project $\left(\mathrm{C}_{0}\right)$ is $\$ 50,000$, then: 


$$
\begin{gathered}
\mathrm{NPV}_{4}=\left[\frac{\pi_{1}}{(1+\mathrm{k})^{1}}+\frac{\pi_{2}}{(1+\mathrm{k})^{2}}+\frac{\pi_{3}}{(1+\mathrm{k})^{3}}+\frac{\pi_{4}}{(1+\mathrm{k})^{4}}\right]-\mathrm{C}_{0} \\
=\left[\frac{38,688}{(1+.12)^{1}}+\frac{38,688}{(1+.12)^{2}}+\frac{38,688}{(1+.12)^{3}}+\frac{38,688}{(1+.12)^{4}}\right]-50,000=[34,543+30,841+27,537+24,587]- \\
50,000=117,508-50,000=67,508
\end{gathered}
$$

This is one estimate of the net present value of a project. If this type of estimation is repeated hundreds of times using different values of the variables taken from their probability distribution, we can eventually form the probability distribution of the general net present value of the project, and we can estimate its mean, as well as its standard deviation, as the level of risk. Suppose that repeated simulation ends up with an expected net present value of $\$ 65,000$ and a standard deviation of 24,000 , we can calculate the $x$-value and obtain the table value that refers to the probability of having a negative net present value: $Z=\frac{x-\bar{x}}{\sigma}=\frac{0-65,000}{24,000}=-2.7$

Looking this value up in the z-table reveals the value of .0035 under the zero column. It means that the zero value is 2.7 standard deviations below the mean and that the probability of the net present value being negative (less than zero) is $35 \%$. In addition to the full fledge process of the mathematical simulation, there are other related techniques to deal with risk but to a less extent. Sensitivity analysis utilizes the same set of variables and their mathematical model, but it stops short of obtaining complete probability distribution to the whole set. It focuses on randomizing the value of one key variable in the model to test the impact of the single change on the rest and establish how sensitive the model is in its response. For example, a sensitivity analysis can be performed on the net present value model by changing the unit price of the product frequently and tracking down the impact of such change on the outcome. Another similar technique is the scenario analysis, which differs from the sensitivity analysis only by extending the random change into more than one variable to see the impact of changing a number of variables simultaneously. While sensitivity and scenario analyses are limited, they are more practical and more commonly used. Full simulation is comprehensive and powerful, but it is more expensive and time consuming, even in the computer age. It can, for most managers, be reserved for only the major cases.

\section{Advanced Choice under Risk, Ambiguity, and Uncertainty}

This is the technical approach to the management choice among a finite number of alternatives using mathematical techniques. It is often possible to quantify economic outcomes used in areas such as policy and cost-benefit analysis conditional on uncontrolled events. Uncontrolled events may include the value of unknown parameters in a response function, the effectiveness of a new technology, weather events, etc. It is to illustrate the decision criteria that are available, assuming that conditional economic outcomes can be determined. (Ben-Hiam, 2006)

The notion of the cumulative distribution function (cdf) is defined as the area under the probability density function (pdf) of a random variable (rv) to the left of a particular value of the rv. Hence, it is the probability that an rv is less than or equal to that value. The cumulative distribution function $\mathrm{F}(\mathrm{x})$ of a random variable $\mathrm{X}$ is the probability that $\mathrm{X}$ has a value that is less than or equal to $\mathrm{x}$; i.e., $\mathrm{F}(\mathrm{x})=\operatorname{Pr}[\mathrm{X} \leq \mathrm{x}]$ 


$$
\begin{aligned}
& \text { For example, if the pdf of } X \text { is } f(x), f(x)=\frac{1}{\sqrt{2 \pi \sigma^{2}}} \exp \left[-\frac{1}{2 \sigma^{2}}(x-\mu)^{2}\right] \text {, then the cdf of } X \text { is } \\
& \qquad F(x)=\int_{\infty}^{x} \frac{1}{\sqrt{2 \sigma^{2}}} \exp \left[-\frac{1}{2 \sigma^{2}}(1-\mu)^{2}\right] d t .
\end{aligned}
$$

The technique that has been developed to identify conditions under which one risky alternative is preferred to another is called the Stochastic dominance.

\subsection{Stochastic Dominance}

It is an approach to identify the preferred alternative while making the weakest possible assumptions. Generally, stochastic dominance assumes an individual is an expected utility maximizer and then adds further assumptions relative to preference. It relies on the appropriateness of expected utility maximization and the underlying assumptions on preference. It should be mentioned that some experimental decision problems from the 1950s and 1960s, such as the Allais Paradox and the Ellsberg paradox, have suggested decision makers don't follow expected utility maximization. On the other hand, some econometric tests with real-world data have tended to support expected utility maximization. The assumptions here are: 1) expected utility maximization, 2) two compared mutually exclusive alternatives, 3) probability distribution of a true population. (Ellsberg, 1961; Katzner, 1998; Kim et al. 2015; Kahn and Sarin, 1988; Kahneman and Tversky, 1979; Segal 1987)

Now, suppose the two alternative decisions yield alternative probability density functions for benefit, $x$; viz., $f(x)$ and $\mathrm{g}(\mathrm{x})$. Expected utilities, $\mathrm{E}[\mathrm{U}(\mathrm{x})]$, corresponding to the different decisions are: $\int_{-\infty}^{\infty} U(x) f(x) d x$ and $\int_{-\infty}^{\infty} U(x) g(x) d x$

The difference in these expected utilities is: $\int_{-\infty}^{\infty} U(x) f(x) d x-\int_{-\infty}^{\infty} U(x) g(x) d x$

$$
\int_{-\infty}^{\infty} U(x)(f(x)-g(x)) d x
$$

Note that the difference is positive when $\mathrm{f}(\mathrm{x})$ yields higher expected utility than $\mathrm{g}(\mathrm{x})$ and negative otherwise.

If positive, $f(x)$ is a preferred gamble to $g(x)$; otherwise, $g(x)$ is a preferred gamble to $f(x)$.

\subsubsection{First-Degree Stochastic Dominance (FSD)}

If we consider $\int_{-\infty}^{\infty} U(x)(f(x)-g(x)) d x$, and let $\mathrm{u}=\mathrm{U}(\mathrm{x})$ and $\mathrm{v}=\mathrm{F}(\mathrm{x})-\mathrm{G}(\mathrm{x})$. Then, use the integration by parts, given that $d u=U^{\prime}(x) d x$ and $d v=(f(x)-g(x)) d x$, we get:

$$
\begin{gathered}
\int_{-\infty}^{\infty} \mathrm{U}(\mathrm{x})[\mathrm{f}(\mathrm{x})-\mathrm{g}(\mathrm{x})] \mathrm{dx}=\left.\mathrm{U}(\mathrm{x})[\mathrm{F}(\mathrm{x})-\mathrm{G}(\mathrm{x})]\right|_{-\infty} ^{\infty}-\left.\right|_{-\infty} ^{\infty} \mathrm{U}^{\prime}(\mathrm{x})[\mathrm{F}(\mathrm{x})-\mathrm{G}(\mathrm{x})] \mathrm{dx} \\
=\mathrm{U}(\infty)[\mathrm{F}(\infty)-\mathrm{G}(\infty)]-\mathrm{U}(-\infty)[\mathrm{F}(-\infty)-\mathrm{G}(-\infty)]-\int_{-\infty}^{\infty} \mathrm{U}^{\prime}(\mathrm{x})[\mathrm{F}(\mathrm{x})-\mathrm{G}(\mathrm{x})] \mathrm{dx} \\
=\mathrm{U}(\infty)(1-1)-\mathrm{U}(-\infty)(0-0)-\int_{-\infty}^{\infty} \mathrm{U}^{\prime}(\mathrm{x})[\mathrm{F}(\mathrm{x})-\mathrm{G}(\mathrm{x})] \mathrm{dx} \\
=\int_{-\infty}^{\infty} \mathrm{U}^{\prime}(\mathrm{x})[\mathrm{G}(\mathrm{x})-\mathrm{F}(\mathrm{x})] \mathrm{dx}
\end{gathered}
$$


Observe that this term is nonnegative if $\mathrm{U}^{\prime}(\mathrm{x})>0$ and $\mathrm{G}(\mathrm{x})>\mathrm{F}(\mathrm{x})$. Probability density function $\mathrm{f}$ dominates probability density function $\mathrm{g}$ by first degree stochastic dominance (FSD) when $\mathrm{U}^{\prime}(\mathrm{x})>0$ if and only if the cumulative distribution function associated with $\mathrm{f}$ is less than or equal to the cumulative distribution function associated with $\mathrm{g}$ (i.e., $\mathrm{F}(\mathrm{x}) \leq \mathrm{G}(\mathrm{x})$ for all $(\mathrm{x})$ and strict inequality holds for at least one $\mathrm{x}$. There are two implications of FSD: 1) the mean of $\mathrm{f}$ is greater than the mean of $\mathrm{g}$, and 2) for every level of probability, at least as much money is made under $f$ as under $g$. This is what can be concluded from characterizing the choice between two alternatives for every expected utility maximizer that prefers more to less.

8.2 Second-Degree Stochastic Dominance (SSD)

If we consider $=\int_{-\infty}^{\infty} U^{\prime}(x)[G(x)-F(x)] d x$, then if this expression is positive, $f$ is preferred to $g$ since the expected utility under $\mathrm{f}$ is greater than the expected utility under $\mathrm{g}$.

Using integration by parts, let $u=U^{\prime}(x)$ and let $d v=[G(x)-F(x)] d x$, and we note that $\mathrm{du}=\mathrm{U}^{\prime \prime}(\mathrm{x})$ and $\mathrm{v}=\int_{-\infty}^{\infty}[\mathrm{G}(\mathrm{t})-\mathrm{F}(\mathrm{t})] \mathrm{dt}$. So :

$$
\int_{-\infty}^{\infty} \mathrm{U}(\mathrm{x})[\mathrm{G}(\mathrm{x})-\mathrm{F}(\mathrm{x})] \mathrm{dx}=\left.\mathrm{U}^{\prime}(\mathrm{x}) \int_{-\infty}^{\mathrm{x}}[\mathrm{G}(\mathrm{t})-\mathrm{F}(\mathrm{t})] \mathrm{dt}\right|_{-\infty} ^{\infty}-\left.\int_{-\infty}^{\infty} \mathrm{U}(\mathrm{x}) \int_{-\infty}^{\mathrm{x}}[\mathrm{G}(\mathrm{t})-\mathrm{F}(\mathrm{t})] \mathrm{dt} \mathrm{dx}\right|_{-\infty} ^{\infty}
$$

Focus on the first term:

$$
\left.\mathrm{U}^{\prime}(\mathrm{x}) \int_{-\infty}^{\mathrm{x}}[\mathrm{G}(\mathrm{t})-\mathrm{F}(\mathrm{t})] \mathrm{dt}\right|_{-\infty} ^{\infty}=\mathrm{U}(\infty) \int_{-\infty}^{\mathrm{x}}[\mathrm{G}(\mathrm{t})-\mathrm{F}(\mathrm{t})] \mathrm{dt}-\mathrm{U}(\infty) \int_{-\infty}^{\infty}[\mathrm{G}(\mathrm{t})-\mathrm{F}(\mathrm{t})] \mathrm{dt}
$$

Assume that $U^{\prime}(x)>0$ and that $\int_{-\infty}^{x}[G(t)-F(t)] d t \geq 0$ with strict inequality for some $x$ (the first assumption is from FSD; the second assumption is new and is used in signing the second term as well). This makes $\int_{-\infty}^{\infty}[G(t)-F(t)] d t \geq 0$ and, of course always, $\int_{-\infty}^{-\infty}[G(t)-F(t)] d t=0$. This makes the first term positive. However, if we focus on the second term:

$$
\left.\int_{-\infty}^{\infty} U^{\prime}(x) \int_{-\infty}^{x}[G(t)-F(t)] d t d x\right|_{-\infty} ^{\infty}
$$

In order to guarantee that $f$ is preferred to $g$ the sign of this whole term must be negative (since the whole term is subtracted). Second degree stochastic dominance (SSD) assumes that the second derivative of the utility function with respect to $x$ is negative everywhere (assume $U^{\prime \prime}(x)<0$ ). With this assumption, if $\int_{-\infty}^{x}[G(t)-F(t)] d t$ $\geq 0$ with strict inequality for at least one $\mathrm{x}$ (this was already assumed in signing the first term) then this makes $\int_{-\infty}^{\infty}[\mathrm{G}(\mathrm{t})-\mathrm{F}(\mathrm{t})] \mathrm{dt} \geq 0$ and, of course always, $\int_{-\infty}^{-\infty}[\mathrm{G}(\mathrm{t})-\mathrm{F}(\mathrm{t})] \mathrm{dt}=0$. These assumptions make the second term negative. The minus sign in front of the second term makes it positive.

Under the assumptions of positive marginal utility (U'(x) > 0 ) and diminishing marginal utility (U' $(\mathrm{x})<0)$, f dominates $g$ by second degree stochastic dominance (SSD) if and only if $\int_{-\infty}^{x}[G(t)-F(t)] d t \geq 0$ for all $x$ with strict inequality for at least one $\mathrm{x}$.

The interpretation of SSD is not difficult. The area under the cumulative distribution function of X, i.e, $F$, up to $\mathrm{x}$ is the expected "shortfall" of X relative to $\mathrm{x}$ (here "shortfall" refers to the difference between a target return (or goal), $\mathrm{x}$, and the outcome). $\mathrm{f}$ dominates $\mathrm{g}$ according to SSD if and only if the expected shortfall under $\mathrm{g}$ relative to target return $\mathrm{x}$ is greater than or equal to the expected shortfall under $\mathrm{f}$ relative to target return $\mathrm{x}$ for all 
possible target returns with "greater than" holding for at least one target return. This interpretation suggests that a risk averse decision maker ranks gambles by how well the gamble is expected to meet a goal (in fact, any goal). 8.2.1 Applications of SSD Conditions

Recall that stochastic dominance analysis uses conditions on the cumulative distribution functions associated with different decisions to derive the set of decisions that can be ruled out as inefficient relative to other decisions in terms of expected utility. The conditions provided by second degree stochastic dominance, which is the work horse among stochastic dominance criteria, are that decision $A_{i}$ is superior to decision $A_{k}$ if and only if $\int_{-\infty}^{\mathrm{x}}\left[\mathrm{F}_{\mathrm{A}_{\mathrm{k}}}(\mathrm{t})-\mathrm{F}_{\mathrm{A}_{\mathrm{i}}}(\mathrm{t})\right] \mathrm{dt} \geq 0$ for all $\mathrm{x}$ with strict inequality for at least one $\mathrm{x}$ where $F_{A_{i}}$ the cumulative distribution function associated with decision $A_{i}$. The left pane of the following Table 6 depicts a policy decision featuring decisions $\left(A_{i}\right)$, events $\left(E_{j}\right)$, event probabilities $\left(P_{j}\right)$, and outcomes conditional on each decision and event $\left(\mathrm{V}\left(A_{i}, E_{j}\right)\right)$ where the latter are shown in the body of the table.

Table 6. A sample of a policy decision with conditional outcome

\begin{tabular}{|c|c|c|c|c|c|c|c|c|c|c|c|}
\hline $\begin{array}{c}\text { Event } \\
\text { Probability } \\
\text { Policy }\end{array}$ & $\mathrm{E}_{1}$ & $\begin{array}{c}\mathrm{E}_{2} \\
.5\end{array}$ & $\begin{array}{r}\mathrm{E}_{3} \\
.3\end{array}$ & $\begin{array}{c}\text { Event } \\
\text { Probability } \\
\text { Policy }\end{array}$ & $\begin{array}{c}\mathrm{E}_{1} \\
{[.15,25]}\end{array}$ & $\begin{array}{c}E_{2} \\
{[.4, .6]}\end{array}$ & $\begin{array}{c}\mathrm{E}_{3} \\
{[.25, .35]}\end{array}$ & $\begin{array}{c}\text { Event } \\
\text { Probability } \\
\text { Policy }\end{array}$ & $E_{1}$ & $\mathrm{E}_{2}$ & $\mathrm{E}_{3}$ \\
\hline $\mathrm{A}_{1}$ & .8 & .9 & 1.0 & $\mathrm{~A}_{1}$ & .8 & .9 & 1.0 & $\mathrm{~A}_{1}$ & .8 & .9 & 1.0 \\
\hline $\mathrm{A}_{2}$ & .8 & 1.1 & 1.3 & $\mathrm{~A}_{2}$ & .8 & 1.1 & 1.3 & $\mathrm{~A}_{2}$ & .8 & 1.1 & 1.3 \\
\hline $\mathrm{A}_{3}$ & .8 & .95 & 1.4 & $\mathrm{~A}_{2}$ & .8 & .95 & 1.4 & $\mathrm{~A}_{3}$ & .8 & .95 & 1.4 \\
\hline
\end{tabular}

\subsection{Choice under Ambiguity}

If the likelihood of uncontrolled events can be determined up to a convex set (e.g., ranges of probability values are known), then there is said to be ambiguity about the risks associated with decision, i.e., decision making under ambiguity. This case represents a middle ground between the risk and uncertainty environments. For such cases, an emerging decision criterion known as maxmin expected utility (Gilboa and Schmeidler, 1989) suggests maximizing the minimum expected utility over the convex set; i.e. with linear utility, decision $A_{i}$ is superior to decision $\mathrm{A}_{\mathrm{k}}$

if Min $E\left[V\left(A_{i}, E_{j}\right)\right]>$ Min $E\left[V\left(A_{k}, E_{j}\right)\right]$ where $P$ is a vector of probabilities associated with $(\mathrm{P} \in \mathrm{S})$ $(\mathrm{P} \in \mathrm{S})$

uncontrolled events and $\mathrm{S}$ is a convex set. The right pane of the Table above shows the decision problem under ambiguity. The maxmin expected utility optimal decision is given by

Maximize $\left(\operatorname{Min} \Sigma_{j} 9 \mathrm{~V}\left(\mathrm{~A}_{\mathrm{i}}, \mathrm{E}_{\mathrm{j}}\right) \mathrm{p}_{\mathrm{j}}\right.$; subject to $\Sigma_{\mathrm{j}} \mathrm{p}_{\mathrm{j}}=1, \mathrm{p}_{\mathrm{j}}=\in\left[\mathrm{a}_{\mathrm{j}}, \mathrm{b}_{\mathrm{j}}\right] \forall \mathrm{j}$. The maxmin expected utility $\mathrm{A}_{\mathrm{i}}$ (P) 
criterion generalizes both expected utility maximization and the maximin criterion in the sense that both criteria are special cases of maxmin expected utility. To see this, observe that the maxmin expected utility optimal decision corresponds to expected utility maximization when $\mathrm{S}$ consists of a single point and corresponds to the maximin criterion when $S$ does not restrict the ranges of possible probabilities ( $\mathrm{S}$ is a unit $\mathrm{n}$-simplex).

Application of maxmin expected utility to the right pane of the Table 6 shows $A_{2}$ to be the optimal choice.

\subsection{Choice under Uncertainty}

Predicting or determining the likelihood of uncontrolled events is often difficult and can involve significant time and expense. In cases where the latter are prohibitive, often referred to as decision making under uncertainty, there are several approaches. Traditional decision criteria, including the maximin, maximax, Laplace, and Hurwicz criteria (Hurwicz, 1951; Render et al., 2009, Stigler 1986)), may be possible. While none of these criteria require knowledge of uncontrolled event probabilities for application, the first two represent polar extremes in terms of optimism and pessimism while the latter two require information similar to probabilities in order to be applied.

The Laplace criterion has come under criticism in the philosophy literature due to what has become known as the paradox of the envelopes. Here is a statement of that decision problem followed by three decision tables which apply the Laplace criterion to the problem and achieve three different optimal solutions.

Situation: Two sealed envelopes (yours and theirs). One contains twice the money of the other. You can keep yours or switch. What should you do?

Table 7. Scenario of the sealed envelopes

Envelopes sealed

\begin{tabular}{|c|c|c|c|}
\hline Event $\rightarrow$ & $\mathrm{E}_{1}$ & $\mathrm{E}_{2}$ & Expected Payoff \\
\hline Probability $\rightarrow$ & $\frac{1}{2}$ & $\frac{1}{2}$ & $\leftarrow$ By Laplace \\
\hline Act $\downarrow$ & Payoff $\downarrow$ & Payoff $\downarrow$ & Optimal Act: Indifferent \\
\hline Keep & $\mathrm{x}$ & $2 \mathrm{x}$ & $\frac{3}{2} \mathrm{x}$ \\
\hline Switch & $2 \mathrm{x}$ & $\mathrm{x}$ & $\frac{3}{2} \mathrm{x}$ \\
\hline
\end{tabular}

Open yours; find $\$ x$

\begin{tabular}{|c|c|c|c|}
\hline Event $\rightarrow$ & $\mathrm{E}_{1}$ & $\mathrm{E}_{2}$ & Expected Payoff \\
\hline Probability $\rightarrow$ & $\frac{1}{2}$ & $\frac{1}{2}$ & \\
\hline Act $\downarrow$ & Payoff $\downarrow$ & Payoff $\downarrow$ & Optimal Act: Switch \\
\hline Keep & $\mathrm{x}$ & $\mathrm{x}$ & $\mathrm{x}$ \\
\hline Switch & $2 \mathrm{x}$ & $\frac{3}{2}$ & $\frac{5}{4} \mathrm{x}$ \\
\hline
\end{tabular}

Open other: find $\$ x$

\begin{tabular}{|c|c|c|c|}
\hline Event $\rightarrow$ & $\mathrm{E}_{1}$ & $\mathrm{E}_{2}$ & Expected Payoff \\
\hline Probability $\rightarrow$ & $\frac{1}{2}$ & $\frac{1}{2}$ & $\leftarrow$ By Laplace \\
\hline Act $\downarrow$ & Payoff $\downarrow$ & Payoff $\downarrow$ & Optimal Act: Keep \\
\hline
\end{tabular}




\begin{tabular}{|c|c|c|c|}
\hline Keep & $2 \mathrm{x}$ & $\frac{\mathrm{x}}{2}$ & $\frac{5}{4} \mathrm{x}$ \\
\hline Switch & $\mathrm{x}$ & $\mathrm{x}$ & $\mathrm{x}$ \\
\hline
\end{tabular}

Putting aside the questions raised by the paradox of the envelopes, each of the criteria for decision making under uncertainty can be interpreted in the context shown in the table. The

maximin optimal decision is found as the solution to Maximize $\operatorname{Min} V\left(A_{i}, E_{j}\right)$; the maximax optimal $\mathrm{A}_{\mathrm{i}} \quad \mathrm{E}_{\mathrm{j}}$

decision is found as the solution to Maximize $\operatorname{Max} V\left(A_{i}, E_{j}\right)$; The Laplace optimal decision is found as

$$
\mathrm{A}_{\mathrm{i}} \quad \mathrm{E}_{\mathrm{j}}
$$

the solution to Maximize $\Sigma_{j} V\left(A_{i}, E_{j}\right)$; the Hurwicz optimal decision (given a value for $w \in[0,1]$ ) is

$$
\mathrm{A}_{\mathrm{i}}
$$

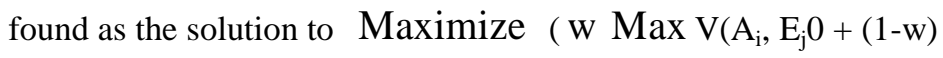

$\mathrm{A}_{\mathrm{i}} \quad \mathrm{E}_{\mathrm{j}}$

Min $V\left(A_{i}, E_{j}\right)$ 0. It is easily verified that application of these criteria to the information in the center pane of $\mathrm{E}_{\mathrm{j}}$

Table 6 gives the following optimal decisions: (maximin, $\mathrm{A}_{1}, \mathrm{~A}_{2}, \mathrm{~A}_{3}$ ) (maximax, $\mathrm{A}_{3}$ ); (Laplace, $\mathrm{A}_{3}$ ), (Hurwicz (w $=.7), \mathrm{A}_{3}$ ).

\section{References}

Acharya, V. V., Lasse, H. P., Philippon, T., \& Richardson, M. (2017). Measuring systematic risk. The Review of Financial Studies, 30(1), 2-47. https://doi.org/10.1093/rfs/hhw088

Alhabeeb, M. J. (2010). Mathematical finance. Hoboken, NJ: Wiley Publications.

Alhabeeb, M. J., \& Moffitt, J. L. (2013). Managerial economics: a mathematical approach. Hoboken, NJ: Wiley Publications.

Baye, M. (2003). Managerial Economics and Business Strategy. McGraw-Hill.

Ben-Haim, Y. (2006). Info-gap Decision Theory: Decisions Under Severe Uncertainty (2nd ed.). Academic Press. https://doi.org/10.1016/B978-012373552-2/50003-5

Ben-Horim, M., \& Levy, H. (1980). Total risk, diversifiable and undiversifiable risks: a pedagogic note. Journal of Financial and Quantitative Analysis, 15(2), 289-297. https://doi.org/10.2307/2330346

Blokdyk, G. (2020). Systematic risk: a complete guide. 5Starcook Publishing.

Brigham, E., \& J. Houston (1999). Fundamentals of Financial Management. The Dryden Press.

Ellsberg, D. (1961). Risk, ambiguity, and the savage axioms. Quarterly Journal of Economics, 75(1), 643-669. https://doi.org/10.2307/1884324

Fama, E. F., \& French, K. R. (1992). The cross-section of expected stock returns. Journal of Finance, 47(2), 
427-65. https://doi.org/10.1111/j.1540-6261.1992.tb04398.x

Fama, E. F., \& Kenneth, R. F. (2004). The capital asset pricing model: theory and evidence. Journal of Economic Perspectives, 25-46. https://doi.org/10.1257/0895330042162430

Gilboa, I., \& Schmeidler, D. (1989). Maximin expected utility with a non-unique prior. Journal of Mathematical Economics, 18(1), 141-153. https://doi.org/10.1016/0304-4068(89)90018-9

Gitman, L. (2008). Principles of Managerial Finance. Reading, MA: Addison-Wesley

Hirschey, M. (2006). Managerial Economics. Thompson South-Western.

Hurwicz, L. (1951). The generalized bayes minimax principle: a criterion for decision making under uncertainty. Cowles Commission Paper \# 355.

Kahn, B. E., \& Sarin, R. K. (1988). Modeling ambiguity in decisions under uncertainty. Journal of Consumer Research, 15(1), 265-272. https://doi.org/10.1086/209163

Kahneman, D., \& Tversky, A. (1979). Prospect theory: an analysis of decision under risk. Econometrica, 47, 263-291. https://doi.org/10.2307/1914185

Kasser, J. (2020). Systemic and systematic risk management. CRC Press. https://doi.org/10.1201/9780429025389

Katzner, D. W. (1998). Time, ignorance, and uncertainty in economic models. The University of Michigan Press. https://doi.org/10.3998/mpub.15445

Keat, P., \& P. Young. (2006). Managerial economics: economic tools for today's decision makers. Pearson-Prentice Hall.

Kim, H. W., Kang, J. I., Namkoong, K., Jhung, K., Ha, R. Y., \& Kim, S. J. (2015). Further evidence of a dissociation between decision-making under ambiguity and decision-making under risk in obsessivecompulsive disorder. Journal of Affective Disorders, 176, 118-124. https://doi.org/10.1016/j.jad.2015.01.060

Knight, F. H. (1921). Risk, uncertainty, and profit. New York, NY: Sentry Press.

Markowitz, H. (1952). Portfolio selection. Journal of Finance, 7, 77-91. https://doi.org/10.1111/j.1540-6261.1952.tb01525.x

Markowitz, H. (1959). Portfolio selection: efficient diversification. John Wily and Sons, Inc.

Modigliani, F., \& Miller, M. (1958). The cost of capital, corporate finance, and the theory of investment. The American Economic Review, 49(4), 655-669.

Perold, A. F. (2004). The Capital asset pricing model. Journal of Economic Perspectives, 3-24. https://doi.org/10.1257/0895330042162340

Render, B., Stair, R. M., \& Hanna, M. E. (2009). Quantitative analysis for management. Upper Saddle River, NJ: Pearson Education, Inc.

Salvatore, D. (2012). Managerial economies in a global economy. Oxford University Press.

Segal, U. (1987). Ellsburg paradox and risk aversion: an anticipated utility approach. International Economic Review, 28(1), 175-202. https://doi.org/10.2307/2526866

Sharpe, W. F. (1964). Capital assets prices: a theory of market equilibrium under conditions of risk. The Journal of Finance, 19(3), 425-442. https://doi.org/10.1111/j.1540-6261.1964.tb02865.x

Stigler, S. M. (1986). The history of statistics: the measurement of uncertainty. Boston, MA: Harvard University Press.

Tobin, J. (1958). Liquidity preferences as behavior towards risk. Review of Economic Studies, 25(2), 65-86. https://doi.org/10.2307/2296205

\section{Copyrights}

Copyright for this article is retained by the author(s), with first publication rights granted to the journal.

This is an open-access article distributed under the terms and conditions of the Creative Commons Attribution license (http://creativecommons.org/licenses/by/4.0/). 